\title{
Application of Team Assisted Individualization Cooperative Learning to Improve Mathematics Learning Multiplication Material
}

\author{
Nurkholidah \\ SD N 02 Karangtengah \\ nurkholidah1105@gmail.com
}

\section{Article History}

accepted 01/11/2020

published 15/11/2020

\begin{abstract}
The purpose of this study was to improve the multiplication material learning Mathematics. This study uses the Team Assisted Individualized Cooperative learning model, namely by grouping students into several groups, each of which contains smart children and less intelligent children. Each group worked on the multiplication questions given by the teacher, children who were good at guiding children who were less intelligent (peer tutors). The results of the study using this learning model showed encouraging results for children who previously had many who were incomplete by using this learning model many children who value above KKM.
\end{abstract}

Keywords : learning mathematics, Cooperative Team Assisted Individualization

\section{Abstrak}

Tujuan penelitian ini adalah untuk meningkatkan pembelajaran Matematika materi perkalian . Penelitian ini menggunakan model pembelajaran Kooperatif Team Assisted Individualizatiaon yaitu dengan mengelompokkkan siswa dalam beberapa kelompok yang tiap kelompok berisi anak yang pandai dan anak yang kurang pandai. Setiap kelompok mengerjakan soal perkalian yang di berikan oleh guru, anak yang pandai membimbing anak yang kurang pandai ( tutor sebaya ).Hasil penelitian dengan menggunakan model pembelajaran ini menunjukkan hasil yang menggembirakan anak yang sebelumnya banyak yang tidak tuntas dengan menggunakan model pembelajaran ini banyak anak yang nilainnya diatas KKM.

Kata Kunci pembelajaran, matematika, kooperatif team assisted individualization

Social, Humanities, and Education Studies (SHEs): Conference Series https://jurnal.uns.ac.id/shes

p-ISSN 2620-9284

e-ISSN 2620-9292 


\section{PENDAHULUAN}

Matematika berhubungan dengan cara mencari fakta- fakta secara sistematis sehingga matematika bukan hanya penguasaan teori saja tetapi sangat di perlukan dalam kehidupan sehari- hari.Matematika sangat penting di ajarkan dan dilaksanakan di SD, maka pada saat pembelajaran guru hendaknya dapat menciptakan situasi pembelajaran yang memungkinkan untuk meningkatkan keaktifan siswa dalam mencari penyelesaian suatu masalah.

Pembelajaran matematika kelas III SD N 02 Karangtengah tentang materi perkalian ditemukan fakta bahwa banyak siswa yang nilainya di bawah KKM 70, hanya 7 siswa yang nilai nya mencapai KKM dari 17 orang siswa, berarti ada 10 siswa yang nilainya masih di bawah KKM. Seorang guru di tuntut untuk dapat menggunakan strategi pembelajaran yang dapat membuat siswa memahami materi yang diajarkan guru, pembelajaran yang menyenangkan dan menarik perhatian siswa, sehingga pemahaman mereka terhadap materi menjadi lebih mudah.Masing - masing siswa yang berbeda membutuhkan layanan yang bisa menggabungkan antar kemampuan antar individu sehingga di bentuk kelompok -kelompok kecil yang heterogen guna mengoptimalkan perkembagan kemampuan mereka.

Model pembelajaran yang penulis gunakan adalah model pembelajaran Kooperatif Team Assisted Individualizatiaon untuk Meningkatkan Pembelajarn Matematika Materi Perkalian yaitu model pembelajaran siswa mengelompokkkan siswa dalam beberapa kelompok yang terdiri dari 3,4 siswa .Tiap kelompok terdiri dari anak yang pandai dan anak yang kurang pandai, setiap kelompok mengerjakan soal perkalian yang di berikan oleh guru, anak yang pandai membimbing anak yang kurang pandai ( tutot sebaya ). Hasil penelitian dengan menggunakan model pembelajaran ini menunjukkan hasil yang menggembirakan anak yang sebelumnya banyak yang tidak tuntas dengan menggunakan model pembelajaran ini banyak anak yang nilainnya diatas KKM.Peneliti meneliti model pembelajaran Kooperatif Team Assisted Individualization sampai III siklus, dan menunjukkan peningkatan hasil pembelajaran yang di harapkan yaitu anak yang tuntas mencapai 16 siswa ( $94 \%$ ) yang tidak tuntas 1 siswa, dengan nilai rata- rata 85,88. Pelaksanaan perbaikan pembelajaran berjalan dengan cukup baik dengan nilai rata- rata ( siklus I.I =61,1 Siklus I.II =67,05 ) dan meningkat menjadi ( Siklus II.I =74,11, Siklus II.II = 83,52 ) dan meningkat lagi menjadi ( Siklus II.I= 84,70 Siklus III. II=85,88).

Kemampuan guru dalam pembelajaran memerlukan model pembelajaran yang menyenangkan siswa dan membuat siswa tertarik untuk mengikuti pembelajaran, sehingga penulis menggunakan model pembelajaran Kooperatif Team Assisted Individualization. Model pembelajaran Kooperatif Team Assisted Individualization ini mengelompokkan siswa dari berbagai karakter dan tingkat kemamapuan siswa dalam menerima pelajaran dijadikan satu kelompok, sehingga siswa yang kurang mampu dalam pelajaran matematika materi perkalian dapat terbantu oleh siswa yang mampu dalam pelajaran ini ( tutor sebaya ).Siswa merasa senang dengan pembelajaran kelompok ini, apalagi siswa yang kurang mampu dalam pelajaran dapat terbantu oleh siswa yang pandai.

Hakikat model pembelajaran Kooperatif Team Assisted Individualization merupakan model pembelajaran yang membentuk kelompok kecil terdiri dari 3,4,5 siswa , yang heterogen dengan latar belakang , cara berfikir yang berbeda untuk saling membantu terhadap siswa lain yang membutuhkan bantuan ( Suyitno,2002.9 ). Dalam model ini siswa yang pandai dapat mengembangkan ketrampilan dan kemampuannya karena di beri kesempatan untuk membimbing siswa lain yang kurang pandai , kemudian siswa yang lemah dapat terbantu mengatasi permasalahan yang di hadapi. Model pembelajaran Kooperatif Team Assisted Individualization memiliki beberapa tahapan dan setiap tahapan tersebut memiliki komponen didalamnya yaitu kelompok, penempatan, perangkat pembelajaran, belajar kelompok, skor kelompok dalam 
pengakuan kelompok, pengajaran kelompok, tes fakta, dan unit - unit kelas keseluruhan.

\section{METODE}

Penelitian ini merupakan penelitian tindakan kelas (PTK) yang dilaksanakan dalam 3 siklus. Penelitian dilakukan dalam tiga siklus. Tiap siklus terdiri dari 2 tahapan yaitu perencanaan, pelaksanaan, obsevasi, dan refleksi. Penelitian ini dilaksanakan pada siswa kelas III di SD Negeri 02 Karangtengah terletak di dusun Kecepit Desa Karangtengah Kecamatan Ampelgading Kabupaten Pemalang Provinsi Jawa Tengah dengan jumlah siswa 17 siswa.

\section{HASIL DAN PEMBAHASAN}

Hasil Penelitian kelas yang dilakukan oleh penulis menunjukkan peningkatan pembelajaran yang diinginkan oleh penulis. Melalui penelitian Tindakan kelas menggunakan model pembelajaran Kooperatif Team Assisted Individualization ada peningkatan hasil belajar siswa mata pelajaran Matematika materi Perkalian, bisa dilihat di tabel pelaksanaan dan peningkatan nilai dari siklus I.I, I.II, II.I ,II.II, III.I, III.II.

Tabel 1. Jadwal Pelaksanaan Siklus

\begin{tabular}{lllll}
\hline NO & Mata pelajaran & Waktu & Perbaikan Siklus & \multicolumn{1}{c}{ Pelaksanaan } \\
\hline 1 & Matematika & 30 menit & Siklus 1.1 & Jumat, 16-10-2020 \\
2 & Matematika & 30 menit & Siklus 1.2 & Senin, 19-10-2020 \\
3 & Matematika & 30 menit & Siklus 2.1 & Rabu,21-10-2020 \\
4 & Matematika & 30 menit & Siklus 2.2 & Sabtu,24-10-2020 \\
5 & Matematika & 30 menit & Siklus 3.1 & Sabtu, 7- 11-2020 \\
6 & Matematika & 30 menit & Siklus 3.2 & Senin, 9-11-2020
\end{tabular}

Tabel 2. Aspek Perbaikan Pembelajaran

\begin{tabular}{|c|c|c|c|c|c|c|}
\hline \multirow[t]{2}{*}{ No } & \multirow[t]{2}{*}{ Aspek Perbaikan Pembelajaran } & \multicolumn{5}{|c|}{ Skala Nilai } \\
\hline & & 1 & 2 & 3 & 4 & 5 \\
\hline 1 & Pemberian Apersepsi & & & $\mathrm{v}$ & & \\
\hline 2 & Pemberian motivasi & & $\mathrm{v}$ & & & \\
\hline 3 & Penggunaan model pembelajarn & & & & $\mathrm{v}$ & \\
\hline 4 & Bahasa & & & & $\mathrm{v}$ & \\
\hline & Jumlah & & 2 & 3 & 8 & \\
\hline & Nilai rata- rata & & & 3,25 & & \\
\hline
\end{tabular}

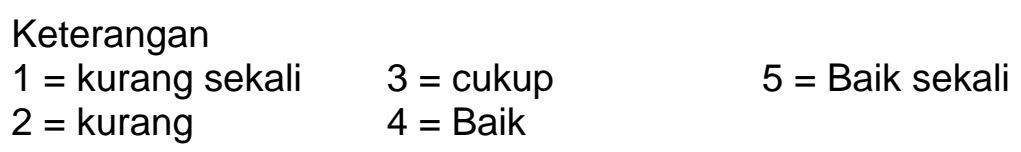

Tabel 3. Penilaian Persiklus

\begin{tabular}{lllllllll}
\hline NO & $\begin{array}{l}\text { NAMA } \\
\text { SISWA }\end{array}$ & PEBELUM & \multicolumn{2}{c}{ SIKLUS I } & \multicolumn{2}{c}{ SIKLUS II } & \multicolumn{2}{c}{ SIKLUS III } \\
& PERAIK & I.I & I.II & II.I & II.II & III.I & III.II \\
\hline 1 & NABIL & 40 & 60 & 60 & 70 & 80 & 80 & 80 \\
2 & AJI ROIF & 40 & 60 & 60 & 70 & 80 & 80 & 80 \\
3 & AZIFATUL & 20 & 40 & 50 & 60 & 60 & 60 & 60 \\
4 & DYAH & 70 & 80 & 80 & 80 & 90 & 90 & 90 \\
5 & DINDA & 40 & 60 & 60 & 70 & 80 & 90 & 90 \\
6 & HASNA & 70 & 80 & 90 & 90 & 100 & 100 & 100 \\
7 & HILMI & 40 & 60 & 60 & 70 & 80 & 90 & 90 \\
\hline
\end{tabular}


SHEs: Conference Series 3 (3) (2020) $62-66$

\begin{tabular}{lllllllll}
\hline 8 & M.AFFAN & 70 & 80 & 90 & 100 & 100 & 100 & 100 \\
9 & M.BINTANG & 70 & 70 & 80 & 80 & 90 & 90 & 90 \\
10 & NATASYA & 40 & 40 & 60 & 70 & 80 & 80 & 80 \\
11 & PUTRI & 40 & 40 & 50 & 60 & 80 & 80 & 80 \\
12 & RADITYA & 40 & 40 & 50 & 60 & 80 & 80 & 80 \\
13 & SHOUMA & 40 & 40 & 50 & 60 & 80 & 80 & 80 \\
14 & SINTA & 40 & 60 & 70 & 80 & 80 & 80 & 80 \\
15 & SYIFA & 70 & 80 & 80 & 80 & 90 & 90 & 100 \\
16 & TAVIV & 70 & 70 & 70 & 80 & 80 & 80 & 80 \\
17 & TIANA & 70 & 80 & 80 & 80 & 90 & 90 & 100 \\
& JUMLAH & 870 & 1.040 & 1.140 & 1.260 & 1.420 & 1.440 & 1.460 \\
& RATA- RATA & 51,1 & 61,1 & 67,05 & 74,11 & 83,52 & 84,70 & 85,88 \\
\hline
\end{tabular}

\section{SIMPULAN}

Pelaksanaan perbaikan pembelajaran berjalan dengan cukup baik dengan nilai rata- rata (siklus I.I =61,1 Siklus $I . I I=67,05$ ) dan meningkat menjadi ( Siklus II.I = 74,11 , Siklus II.II = 83,52 ) dan meningkat lagi menjadi ( Siklus II.I=84,70 Siklus III.II=85,88). Agar siswa lebih aktif dan paham dalam pembelajaran maka cara-cara yang harus kita lakukan,yaitu:

a. Penggunaan model pembelajaran meningkatkan aktifitas - aktifitas siswa dalam pembelajaran dan meningkatkan prestasi siswa.

b. Libatkanlah siswa dalam setiap kegiatan pembelajaran agar siswa antusias dan aktif dalam pembelajaran.

c. Berilah stimulus kepada siswa agar dapat mengembangkan ide dan gagasannya.

d. Adanya pengkondisian kelas yang baik serta pengelolaan sumber belajar, sarana dan prasarana akan meningkatkan prestasi belajar siswa pada suatu kelas.

e. Berilah perhatian lebih kepada siswa sehingga siswa akan merasa diperhatikan dan dilindungi.

Bertolak dari hasil - hasil penelitian yang di peroleh penulis menyampaikan . Saran kepada rekan -rekan guru dalam pembelajaran matematika supaya siswa mencapai prestasi belajar yang baik guru hendaknya memperhatikan Pemberian apersepsi yang menyeluruh dan mengena, sehingga siswa akan teringat kembali terhadap materi yang telah lalu dan siswa akan mempunyai gambaran terhadap materi yang akan disampaikan, Keterlibatan siswa dalam setiap kegiatan pembelajaran sangat di perlukan agar siswa aktif, kreatif, antusias dan merasa senang atau tidak merasa di paksakan dalam menerima materi, Mengaktifkan siswa dalam diskusi kelompok dan penugasan individu untuk menemukan sendiri jawaban dan memupuk rasa tanggung jawab, Pemanfaatan model pembelajaran yang tepat untuk perkalian bersusun dengan hasil 3 atau 4 angka, Di samping itu karena terbukti Penelitian Tindakan Kelas ( PTK ) meningkatkan prestasi belajar siswa, penulis menyarankan kepada rekan - rekan untuk mempelajari dan melakukan Penelitian Tindakan Kelas ( PTK ) di kelasnya masing - masing. Pemahaman PTK ini dapat ditempuh melalui pertemuan Kelompok Kerja Guru (KKG) maupun seminar- seminar penulisan karya tulis ilmiah tentang PTK. 
SHEs: Conference Series 3 (3) (2020) $62-66$

\section{DAFTAR PUSTAKA}

Anggoro .M.T, d. (2010). Metode Penelitian, Jakarta,Universitas terbuka. Jakarta: Universitas Terbuka.

Departemen Pendidikan Naional. (2006). Jakarta : Departemant Pendidikan Nasional Muhsetyo Gatot, d. (2011). Pembelajaran Matematika SD. Jakarta: Universitas Terbuka.

Nana , S. (1995). Dasar- dasar proses belajar mengajar. Bandung: Sinar Baru Algansindo.

Prasetyo. (2002). Strategi Belajar Mengajar. Salatiga: Salatiga Widyasari Press.

Taufiq Agus, d. (2011). Pendidikan Anak di SD. Jakarta: Universitas Terbuka.

Wardani, I. (2004). Penelitian Tindakan Kelas . Jakarta : Universitas Terbuka.

Winataputra, U. (2001). Strategi Belajar Mengajar,Jakarta,. Jakarta: Universitas Terbuka. 